\title{
Long-term dynamics of shrub facilitation shape the mixing of evergreen and deciduous oaks in Mediterranean abandoned fields
}

\author{
Verónica Cruz-Alonso $^{1}$ (D) | Pedro Villar-Salvador ${ }^{1}$ (D) | Paloma Ruiz-Benito ${ }^{1,2}$ (D) | \\ Inés Ibáñez ${ }^{3}$ (D) | José M. Rey-Benayas ${ }^{1}$
}

${ }^{1}$ Departamento de Ciencias de la Vida, Forest Ecology and Restoration Group, Universidad de Alcalá, Madrid, Spain

${ }^{2}$ Departamento de Biología y Geología, Física y Química Inorgánica, Escuela Superior de Ciencias Experimentales y Tecnología, Universidad Rey Juan Carlos, Madrid, Spain

${ }^{3}$ School for Environment and Sustainability, University of Michigan, Ann Arbor, MI, USA

\section{Correspondence}

Verónica Cruz-Alonso

Email:veronica.cral@gmail.com

Funding information

Fundación Internacional para la

Restauración de Ecosistemas; University of Alcalá, Grant/Award Number: FIRE-UAH 127/2017; 'Tatiana Pérez de Guzmán el Bueno' Foundation; REMEDINAL Postdoctoral Fellowship Programme, Grant/ Award Number: TE-CM S2018/EMT-4338; TALENTO Fellow Programme, Grant/Award Number: 2016-T2/AMB-1665

Handling Editor: Cristina García

\section{Abstract}

1. Recovery of Mediterranean forests after field abandonment is a slow process, even without propagule limitations. This is mainly due to stressful conditions for seedling establishment. In this context, shrubs play a critical role in facilitating tree recruitment, but how this process unfolds after field abandonment is not entirely known. We evaluated the long-term dynamics of facilitation by the nurse shrub Retama sphaerocarpa in the recruitment of two ecologically contrasting oaks, the evergreen Quercus ilex and the deciduous Quercus faginea.

2. Thirty years after field abandonment, we dated shrubs and oaks established in an old field to estimate the annual recruitment rates and investigate temporal recruitment patterns. For oaks, we differentiated recruitment at two microsites: open areas or under shrub. To assess how nurse shrubs modulated environmental stressors, we modelled oak recruitment as a function of climatic variables. For the evergreen oak, we assessed these effects within each microsite. Finally, we estimated the annual interaction index between shrubs and evergreen oak juveniles as a function of climatic conditions.

3. Each species showed different recruitment pulses during colonization. Recruitment rate was the highest for the shrub, followed by the evergreen oak. Oak colonization under shrubs was appreciable 20 years after field abandonment, when shrub cover reached $2.2 \%$, and concentrated under medium and large shrubs older than 7 years. Shrubs not only accelerated evergreen oak colonization but also attenuated the fluctuations of recruitment pulses. For the evergreen oak, the interaction index indicated facilitation dominance in years with more arid summers (precipitation $<47 \mathrm{~mm}$ and heat waves longer than 8 days) and competition in wetter summers.

4. Synthesis. Oak colonization in Mediterranean abandoned fields progressed slowly, and only two decades after abandonment pioneer shrub population grew to a level in size and number that could effectively trigger facilitation and accelerate tree recruitment. The shrub nurse effect was unbalanced between oak species, only benefiting the evergreen oak, and it was more prevalent in arid years. Our 
study illustrates the build-up of shrub facilitation during forest recolonization and the varying nature of this process among climatically different years and ecologically distinct species. This information provides insights for assessing and managing Mediterranean forest recovery.

\section{KEYWORDS}

colonization, facilitation, forest recovery, nurse shrub, Quercus, recruitment pulses, Retama sphaerocarpa, secondary succession

\section{1 | INTRODUCTION}

Plants have to overcome several abiotic environmental filters to establish (Harper, 1977; Lortie et al., 2004). The balance of positive and negative biotic interactions, particularly of facilitation and competition, modulates the effect of such filters (Connell \& Slatyer, 1977; Pulsford, Lindenmayer, \& Driscoll, 2016). In forest succession, plant colonizers can facilitate the establishment of mid- and late-successional plant species into the community through environmental modifications (e.g. Butterfield et al., 2010). Generally, the importance of facilitation increases with environmental stress (the so-called Stress Gradient Hypothesis; Bertness \& Callaway, 1994). However, competition can prevail in plant-plant interactions if environmental conditions become very stressful and the abiotic stress is resource driven (e.g. by water shortage or light competition; Maestre, Callaway, Valladares, \& Lortie, 2009; Maestre, Valladares, \& Reynolds, 2005).

In arid and semi-arid ecosystems such as those found in Mediterranean-climate areas, high irradiance and drought are the main abiotic factors affecting early plant establishment (Joffre, Rambal, \& Damesin, 2007; Sánchez-Gómez, Valladares, \& Zavala, 2006), constraining spring seedling emergence and first-summer survival (Mendoza, Zamora, \& Castro, 2009; Rolo, Plieninger, \& Moreno, 2013). Semi-arid ecosystems also show high inter-annual climatic variation that can cause irregular recruitment pulses (Giorgi \& Lionello, 2008; Kouba, Camarero, \& Alados, 2012; Pérez-Ramos, Padilla-Díaz, Koenig, \& Marañón, 2015; Pugnaire, Luque, Armas, \& Gutiérrez, 2006). Thus, chronic water stress and inter-annual climatic variation slow down forest recovery after disturbances (Rey Benayas, Martínez-Baroja, Pérez-Camacho, Villar-Salvador, \& Holl, 2015).

Under stress conditions, shrubs can ameliorate environmental stressors at low competitive costs (Gómez-Aparicio, 2009), facilitating the establishment of mid- and late-successional woody species (Smit, Díaz, \& Jansen, 2009; Smit, Ouden, \& Díaz, 2008). Nurse shrubs can ameliorate climatic constraints and promote soil fertility (i.e. direct facilitation; Gómez-Aparicio, Zamora, Castro, \& Hódar, 2008; Prieto, Padilla, Armas, \& Pugnaire, 2011; Pugnaire et al., 1996), but also attract seed dispersers and reduce herbivory or competition with other plants (i.e. indirect facilitation; Cuesta, Villar-Salvador, Puértolas, Rey Benayas, \& Michalet, 2010; Perea, López-Sánchez,
\& Dirzo, 2017). The facilitative effect of shrubs have been related to specific functional attributes such as plant size (Alday, Zaldívar, Torroba-Balmori, Fernández-Santos, \& Martínez-Ruiz, 2016; Navarro-Cano, Goberna, Valiente-Banuet, \& Verdú, 2016), the root architecture (Prieto, Kikvidze, \& Pugnaire, 2010; Prieto et al., 2011; Rolo et al., 2013) and the ability to fix nitrogen into the soil (GómezAparicio, Zamora, Gómez, Hódar, \& Castro, 2004).

The presence of nurse shrubs could be particularly relevant in facilitating the recruitment of less stress tolerant and more palatable species (Gómez-Aparicio et al., 2008; Liancourt, Callaway, \& Michalet, 2005), expanding their ecological niche and allowing the coexistence of ecologically distinct species (Bruno, Stachowicz, \& Bertness, 2003). In Mediterranean forests, like our study system, evergreen and deciduous oaks frequently co-occur (Madrigal-González et al., 2017). Evergreen oaks have more robust leaves with more leaf mass per area and less $\mathrm{N}$ concentration than deciduous oaks (Castro-Díez, Villar-Salvador, Pérez-Rontomé, Maestro-Martínez, \& Montserrat-Martí, 1997; Gil-Pelegrín, Peguero-Pina, \& SanchoKnapik, 2017). These traits are usually linked to high drought tolerance and low palatability in oak species (Corcuera, Camarero, \& Gil-Pelegrín, 2002; Quero, Villar, Marañón, \& Zamora, 2006). Thus, we could expect evergreen oaks establishing earlier than deciduous oaks during forest succession in open environments, and deciduous oaks being more dependent on nurse shrubs for their recruitment.

Most research on facilitation has been addressed by shortterm studies. However, some studies have focused on the shifts of facilitation over ontogenetic stages of the nurse shrub or of the benefactor (Alday et al., 2016; Moreno-Gutiérrez, Battipaglia, Cherubini, Delgado Huertas, \& Querejeta, 2015; Navarro-Cano et al., 2016; Rousset \& Lepart, 2000; Torroba-Balmori, Zaldívar, Alday, Fernández-Santos, \& Martínez-Ruiz, 2015), and on the covariation of seedling and shrub abundance (Ramírez \& Díaz, 2008), while others have assessed the effect of inter-annual climatic variations on facilitation (Butterfield et al., 2010). Despite these efforts, as far as we know, a long-term and holistic approach evaluating how facilitative effects change after field abandonment has never been addressed. This knowledge gap hinders our understanding of the dynamics associated with facilitation in plant community recovery (Bertness \& Callaway, 1994; Maestre et al., 2005). For example, we know little about how long after field abandonment the nurse shrub community 
takes to start facilitating recruitment of other species, how the effects of facilitation vary among competing beneficiary species and how these effects vary with environmental conditions.

To investigate the dynamics of nurse shrub facilitation we studied colonization of a Mediterranean oak forest over 30 years after field abandonment. Specifically, we assessed the effect of the nurse shrub Retama sphaerocarpa (L.) Boiss. on the long-term recruitment of the evergreen oak Quercus ilex L. and the deciduous oak Quercus faginea Lam. Our objectives were to: (a) compare the long-term recruitment dynamics of the nurse shrub and the oaks after field abandonment; (b) quantify the time lag between field abandonment and the nurse shrub facilitative effect on oak colonization; and (c) evaluate the effects of the nurse shrub on the recruitment patterns of the oaks and the climatic constraints that limit their recruitment. We hypothesised that: (a) recruitment patterns follow temporal pulses that differ among pioneer nurse shrubs and mid- or late successional oaks; (b) there is a time lapse between field abandonment and the acceleration of oak recruitment linked to shrub size and the development of shrub population; and (c) oak recruitment under nurse shrubs is decoupled from recruitment in open sites due to shrub buffering of harsh climate conditions. Understanding how climate and the facilitation-competition balance drive the temporal patterns of oak recruitment will allow for more informed assessment of future forest recovery and a better design of restoration efforts.

\section{2 | MATERIALS AND METHODS}

\section{1 | Study area}

The studied abandoned fields are located on two flat fluvial terraces of the Jarama river in Uceda, Central Spain (700-750 m a.s.I., UTM X: 462 830; UTM Y: 4524 000; ETRS89 30N; Figure 1). The area has a continental Mediterranean climate, with a mean annual temperature of $13^{\circ} \mathrm{C}$ that ranges between 23 and $4^{\circ} \mathrm{C}$ in the hottest and coldest months respectively. The annual rainfall is $500 \mathrm{~mm}$, being c. $60 \mathrm{~mm}$ during the summer (Tornero Sánchez, 1998). The soils are mainly alfisols and inceptisols, with sandy loam to sandy clay loam textures (Peñuelas-Rubira et al., 1996). Agricultural use ceased in c. 1984, although occasional sheep and goat grazing has remained in the area. Currently, oak seedling mortality by herbivory represent less than a quarter of mortality by desiccation (unpublished data). Since 1985, the fields have progressively changed to a shrubland dominated by $R$. sphaerocarpa, a leguminous shrub and a paradigmatic nurse species in the Mediterranean basin (Andivia, Villar-Salvador, Tovar, Rabasa, \& Rey-Benayas, 2017; Cuesta et al., 2010; Pugnaire et al., 1996; Rolo et al., 2013). The abandoned fields are adjacent to mixed forests dominated by Q. ilex and Q. faginea in different proportions (Table S1.1). Quercus faginea acorn dispersal is earlier than Q. ilex's (Castro-Díez \& Montserrat-Martí, 1998). In 2017, when our fieldwork took place, the density of Q. ilex and Q. faginea juveniles were $45 \pm 49$ and $15 \pm 31$ individual/ha (mean $\pm S D$ ) respectively (KruskalWallis $\chi^{2}=9.17 ; p=.002$ ).

\section{2 | Field work and oak recruitment dating}

In the abandoned fields of the study site, we surveyed 20 rectangular transects $(20 \times 60 \mathrm{~m})$ perpendicular to the forest border (Figure 1). In the adjacent forest, the diameter at breast height (d.b.h.) of each oak species was measured in one $20 \times 35$ m plot next to each transect. In each plot, the basal area was calculated using individuals with d.b.h. $>8 \mathrm{~cm}$. The location of transects was selected to sample a wide range of shrub cover and abundance of the two oak species that were representative of the adjacent forest (Table S1.1).

In each transect, we located and harvested all juvenile oaks (namely 105 evergreen oaks and 36 deciduous oaks) during early spring of 2017. To harvest the juveniles, we excavated the ground around the upper part of the tap root and cut a transversal section at the root collar, that is, slightly below the ground level (Figure S2.1a). We then used a dendrochronological approach to date the year of oak recruitment (details in Appendix S2) and reconstruct the $R$. sphaerocarpa shrubland structure along time using allometric models (details in Appendix S3). The microsites where oak juveniles grew were recorded as 'open' or 'under shrub'. To ensure that we assigned the right microsite during recruitment, some records under shrub were corrected to open if (a) the oak was older than the shrub (15 cases in 7 transects $-25 \%$ of all records-), or (b) the shrub was $<5$ years older than the oak and the distance between the oak and shrub stems was less than the predicted crown radius of the shrub in the oak recruitment year ( 5 cases in 3 transects $-8 \%$ of all records-).

\section{3 | Climate data}

We downloaded daily weather data for the study period (1985-2014) from nine meteorological stations close to our study area (http://
FIGURE 1 Location of the study area and the 20 transects where Retama sphaerocarpa (retama) and oak (Quercus ilex and $Q$. faginea) recruitment were sampled

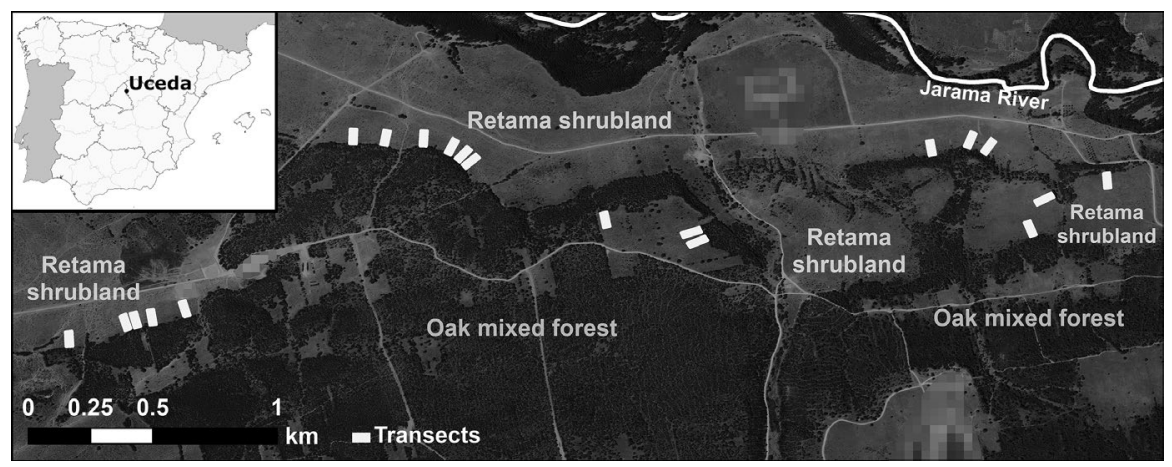


www.aemet.es/es/datos_abiertos/AEMET_OpenData; Figure S1.1). We interpolated the maximum temperature and the precipitation to our study area using the METEOLAND package (De Cáceres, Martin, Granda, \& Cabon, 2018) in R 3.4.3 (R Core Team, 2017). This method interpolates climatic data to a specific area by correcting the original data according to the proximity and elevation differences between the meteorological station and the target area. For each year, we calculated the spring precipitation as the sum of April and May precipitation, the summer precipitation as the sum of July, August and September precipitation, and the length of heat waves as the maximum number of consecutive days with maximum temperature $\geq 33^{\circ} \mathrm{C}$.

\subsection{Data analysis}

\subsection{1 | Long-term dynamics of Retama sphaerocarpa and oak recruitment}

We calculated recruitment rate (no. recruits transect ${ }^{-1}$ year ${ }^{-1}$ ) of $R$. sphaerocarpa, evergreen and deciduous oaks from 1985 to 2014. We used a generalized additive model and the recruitment rate of each species to analyse recruitment patterns over time. For the evergreen oak we differentiated between microsites (open and under shrub). We could not account for microsite differences for the deciduous oak due to the low number of recruits under shrubs. We choose a Poisson error distribution and the smoothing spline method to fit the models with the GAM package (Hastie, 2018) in R 3.4.3 (R Core Team, 2017). We used the Akaike Information Criterion (AIC; Burnham \& Anderson, 2002) to compare models adjusted with different number of knots (i.e. data division points), and we selected the number of knots resulting in minimum AIC (e.g. in Thorson, Punt, \& Nel, 2012).

\subsection{2 | Oak colonization in relation to nurse shrub structure}

We analysed the relationship between oak recruitment and the structure of the $R$. sphaerocarpa shrubland (i.e. density and size structure of shrubs) with a three-step analysis. First, we adjusted generalized additive models for the accumulated recruitment (total and per microsite) of both oak species (recruits transect ${ }^{-1}$ ), using the year as explanatory variable and the model details (i.e. error distribution, algorithms and number of knots) described in the previous section. Second, we identified change points over the fitted curves (i.e. the first year of a new regime of variance of accumulated recruitment) using the cpt.var function of the CHANGEPOINT package (Killick, Haynes, \& Eckley, 2016). The change point was identified with the PELT method and the penalty set manually based on the elbow plot criterion (Figure S1.2). Change points represented acceleration in the recruitment when they separated curve segments of increasing slope. Third, we compared the change years of the accumulated oak recruitment with the change years in each microsite to assess if the acceleration of the oak recruitment was due to recruitment under shrub (i.e. facilitated recruitment). Then, we described the density and size structure of the shrubland when facilitated recruitment occurred.

To study the relationship between oak recruitment and $R$. sphaerocarpa size, we compared (a) the maximum branch diameter of nurse shrubs (i.e. with oaks recruited under their canopies) and of shrubs without recruits using a Kruskal-Wallis test; and (b) the size structure of the R. sphaerocarpa populations with and without recruited oaks. For those comparisons, we only used the data of years and transects with oak recruitment under shrubs.

\subsubsection{Shrub modulation of the climatic effects on oak recruitment}

To assess the effect of climatic variables on the evergreen oak recruitment rates, and how the nurse shrubs might have influenced this process, we used the annual oak recruitment rates estimated since 2005, which was the recruitment year of the oldest oak found under shrub. There were not enough deciduous oak recruits under shrub to make this analysis, so we assessed only the effect of the climate in total recruitment. We focused on climatic conditions during spring and summer, the most limiting periods for seedling survival (Gómez-Aparicio et al., 2004; Mendoza, GómezAparicio, Zamora, \& Matías, 2009). We selected climatic variables that drive spring emergence (spring precipitation in $\mathrm{mm}, \mathrm{SpPrec}_{\mathrm{i}}$ ) and summer survival (summer precipitation in $\mathrm{mm}$, SuPrec $\mathrm{P}_{i}$; length of heat waves in no. days, HtWaves $)$. To control for differences on seed availability among transects, we included the basal area of each target oak species in the adjacent forest $\left(B A_{i}, m^{2} /\right.$ ha). We also considered the year of recruitment as a random variable (YRE) to account for likely temporal processes such as masting, and included an intercept term for each transect to, again, account for differences among transects. For each transect $i$ and year $y$ the observed number of recruits per microsite (COUNT (,$y$, microsite ) was analysed as:

$$
\text { Likelihood: Count } t_{i, y, \text { microsite }} \sim \text { Poisson }\left(\lambda_{i, y, \text { microsite }}\right)
$$

Process model:

$$
\begin{aligned}
& \ln \left(\lambda_{i, y, \text { microsite }}\right)= \alpha_{i}+\beta \cdot \mathrm{BA}_{i}+\gamma 1_{\text {microsite }} \cdot \text { SpPrec }_{y} \\
&+\gamma 2_{\text {microsite }} \cdot \text { SuPrec }_{y} \\
&+\gamma 3_{\text {microsite }} \cdot \text { HtWaves } \\
& y
\end{aligned}
$$

We also included an error term $\varepsilon_{i, y}$ to account for over-dispersion in the recruitment rates (i.e., the variance of the number of recruits was higher than the mean; Kéry, 2010).

We estimated the parameters in Equation (1) with a Bayesian approach and non-informative hyperparameter values (Simpson, Rue, Martins, Riebler, \& Sørbye, 2015). We used the RJAGs package (Plummer, 2016) in R 3.4.3 (R Core Team, 2017) and simultaneously ran three Markov chains with a burn-in period of 500,000 iterations and a sampling period after convergence of 100,000 iterations, 
(a) Retama

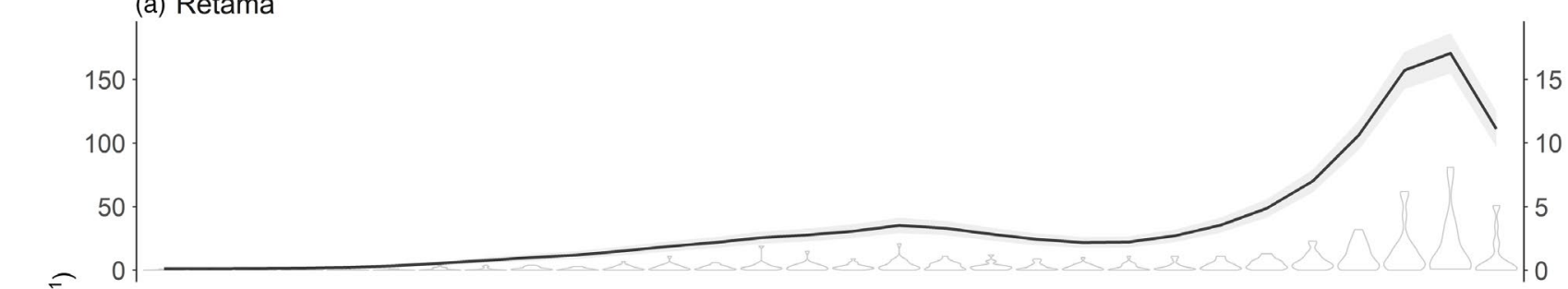

(b) Evergreen oak

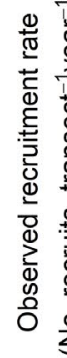

6
4
2.
0

- All — Open — Under shrub

(c) Deciduous oak

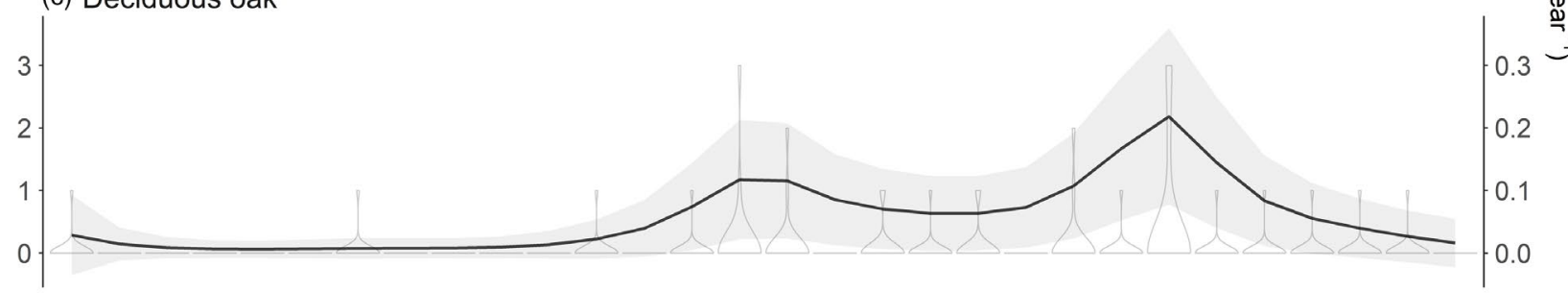

(d) Climate

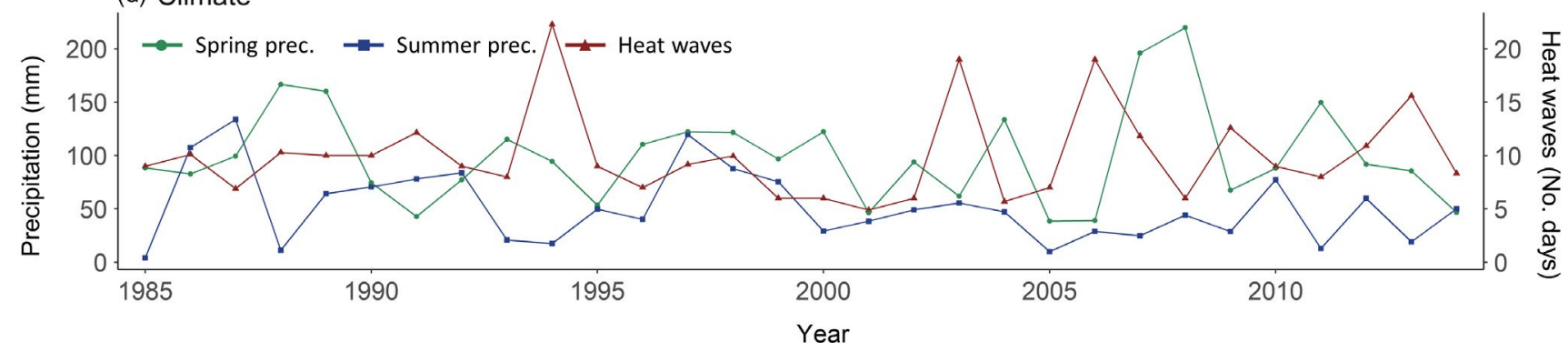

FI GURE 2 Predicted (lines) and observed (violin plots) recruitment rate over time of: (a) the nurse shrub Retama sphaerocarpa (retama); (b) Quercus ilex (evergreen oak); and (c) Quercus faginea (deciduous oak). For the evergreen oak, predicted recruitment rates in open and under shrub microsites are also shown. Note that the scale of recruitment rate differs among species and that all violin plots are represented with the same maximum width. (d) Spring and summer precipitation and length of heat waves along the study period [Colour figure can be viewed at wileyonlinelibrary.com]

during which we recorded the parameter thinning every 100th iteration (see Table S1.2 for results of convergence diagnosis).

To assess if the effect of the shrub on oak recruitment varied across years as a function of climatic conditions, we estimated the intensity of shrub facilitation or competition on evergreen oak establishment with an interaction index. This index was estimated as the difference between oak recruitment under shrub and recruitment in open sites, in years and transects when at least one oak recruited (Gómez-Aparicio et al., 2004). We could not calculate the interaction index for the deciduous oak due to the lack of recruitment under shrub. We then run linear mixed models to ascertain the extent of the interaction index. We used quadratic and linear variants, as a function of each climatic variable (i.e. spring precipitation, summer precipitation or length of heat waves, all standardized). We used LMER function of LME4 package in R 3.4.3 to fit the models, with a Gaussian error distribution (Bates et al., 2017; R Core Team, 2017).
To account for the higher chances of recruiting under a shrub with increasing shrub cover, we included shrub abundance (i.e. the sum of the basal area of each shrub's widest branch, $\mathrm{m}^{2} / \mathrm{ha}$, standardized) as a covariate in the models. We also included transect as a random effect to account for fine grain environmental heterogeneity related to the clustered nature of our sampling.

\section{3 | RESULTS}

\section{1 | Dynamics of Retama sphaerocarpa and oak recruitment}

All species showed two pulses of recruitment that varied in amplitude (i.e. maximum recruitment rate) and length (i.e. duration of the pulses; Figure 2, Table S4.1). Species recruitment pulses occurred at different years: in 2001 and 2013 for R. sphaerocarpa, 1994 and 2008 

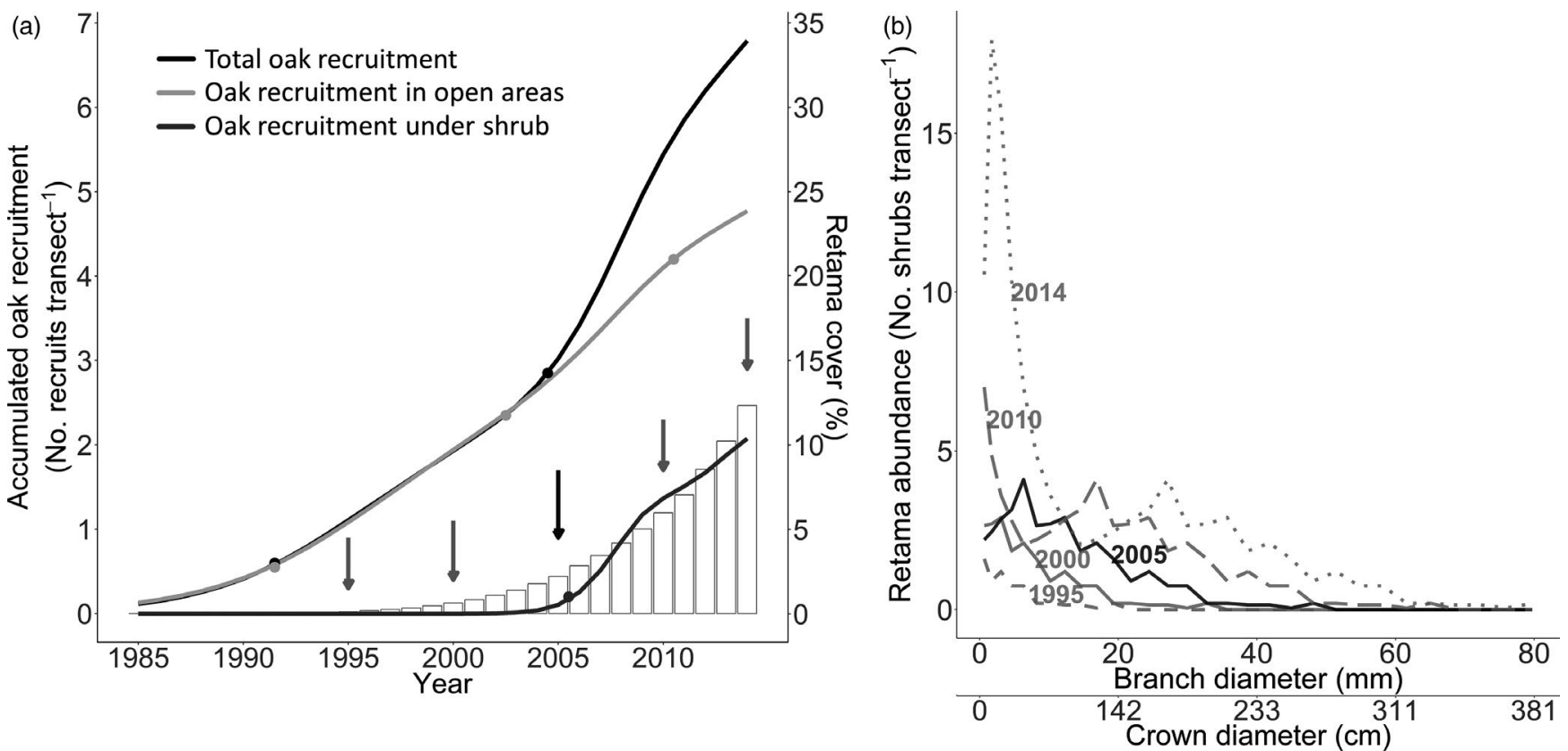

FIGURE 3 (a) Accumulated recruitment over time for both oak species together (lines) and cover of the nurse shrub Retama sphaerocarpa (retama) each year (bars). The dots on lines represent change points in the temporal series of oak recruitment (i.e. acceleration in the recruitment rate when the curve has an increasing slope). The arrows represent the years selected to show the size structure of $R$. sphaerocarpa shrubland in panel b. The black arrow pointing to the black dot represents the change point when oak recruitment under shrub started. (b) Size structure of $R$. sphaerocarpa (retama) shrubland in the abandoned fields for the selected years

for the evergreen oak, and 1999-2000 and 2008 for the deciduous oak. The second pulse was higher than the first pulse for the three species (Figure 2). The amplitude and length of $R$. sphaerocarpa recruitment pulses were remarkably higher than those of oak species (Figure 2a). Pulses of deciduous oak recruitment were less ample and more episodic than pulses of the evergreen oak (Figure S4.1, violin plots in Figure 2b,c). Specifically, the deciduous oak recruitment was null in many years between 1985 and 1996 and it became more regular after 1997 but at a lower rate than the recruitment of the evergreen oak.

The observed recruitment of evergreen oaks under shrub started in 2005 (Figure 2b), 20 years after field abandonment. After that year, evergreen oak recruitment density was 1.5 times greater under shrub than in open areas. This recruitment under shrub represented $38 \%$ of total evergreen oak recruitment in the studied period (1985-2014). After the peak recruitment in 2008 , recruitment rates remained constant under the shrub but considerably decreased in the open areas (Figure 2b). There were only three recruits of the deciduous oak under shrub (i.e. $9 \%$ of total deciduous oak recruitment), all of them in 2008.

\section{2 | Oak colonization in relation to nurse shrub structure}

The change point analysis revealed that total oak recruitment accelerated twice during the study period, between 1991 and 1992 and between 2004 and 2005 (black line in Figure 3a, Table S4.2). While the first change coincided with an acceleration of oak recruitment in open areas, the second change coincided with the beginning and acceleration of oak recruitment under shrub (2005-2006; Figure 3a). By 2005, the estimated $R$. sphaerocarpa shrubland density was $276 \pm 246$ [0-1108] shrubs/ha (mean $\pm S D$ [min-max]), and $R$. sphaerocarpa canopy cover was $2.21 \pm 1.80 \%$ [0\%-7.16\%]. Most of the shrubs were small (branch diameter $<10 \mathrm{~mm}$ ) or medium (branch diameter 10-40 mm, Figure 3b).

Retama sphaerocarpa shrubs with recruited oaks underneath were larger (25.4 [8.2-65.1] mm of branch diameter and 168.6 [75.4329.2] cm of crown diameter; mean [min-max]) than shrubs without oaks (14.5 [0.6-76.0] $\mathrm{mm}$ and 112.9 [12.4-367.4] cm respectively; Kruskal-Wallis $\chi^{2}=25.4 ; p<.001$ ). Oak recruitment only took place in a small fraction of the R. sphaerocarpa population (3.1\% [0.5-9.1]), but this fraction was higher when only big (branch diameter $>40 \mathrm{~mm}$ ) or medium R. sphaerocarpa shrubs were considered (15\% [0-100] and $5.4 \%$ [0-16.7], respectively). Oak recruits were recorded only under R. sphaerocarpa shrubs that were at least 7-8 years old with branch and crown diameters $>8 \mathrm{~mm}$ and $74 \mathrm{~cm}$ respectively (dashed vertical line in Figure 4). Most of the $R$. sphaerocarpa shrubs that contained oaks under their canopy were medium-sized (85.7\%; shaded area in Figure 4), which represented $57.9 \%$ of all the $R$. sphaerocarpa shrubs. In contrast, small and big shrubs contained only $5.7 \%$ and $8.6 \%$ of the oak recruits and represented $39.3 \%$ and $2.8 \%$ of the shrubs respectively.

\subsection{Shrub modulation of the climatic effects on oak recruitment}

The results of the model of Equation (1) indicated that there were no statistically significant effects of the climatic variables on the recruitment rate of evergreen oaks in any of the two microsites (Figure 5a, model parameters in Table S4.3). Collinearity among 


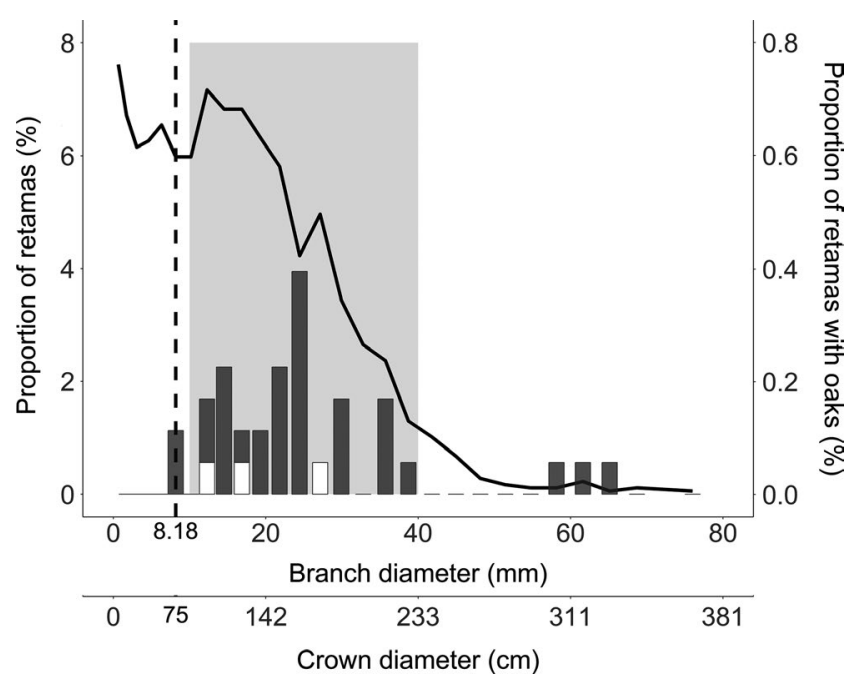

FIGURE 4 Size class distribution of Retama sphaerocarpa (retama) population (line). The filled bar portion represents the fraction of $R$. sphaerocarpa individuals with Quercus ilex (evergreen oak) and the unfilled portion represents the fraction of individuals with Quercus faginea (deciduous oak) underneath. The dashed line represents the minimum $R$. sphaerocarpa size with an oak underneath. The shaded area represents the medium size individuals of $R$. sphaerocarpa

explanatory variables in Equation (1) was low $(-0.27 \leq \rho \leq 0.34$; VIF $\leq 1.20$; Dormann et al., 2013), and the fit of the model $\left(R^{2}\right)$ was .94 (Figure S1.3). There were not statistically significant effects of the climatic variables on recruitment rate of deciduous oaks either (Figure 5b, model parameters in Table S4.3).

The linear models for the interaction index between $R$. sphaerocarpa and evergreen oak recruitment had the best fit (AIC in Table S4.4). Spring precipitation did not have a significant effect on the interaction index (Table S4.5). However, the interaction index was inversely related to summer precipitation and directly related to the length of heat waves (Figure 6, Table S4.5). The effect of the nurse shrub become predominantly negative (i.e. recruitment under shrubs was lower than in open areas; Figure S4.2) when summer precipitation was $>47 \mathrm{~mm}$ or the heat waves lasted < 8 days (Figure 6). Precipitation $>47 \mathrm{~mm}$ or heat waves shorter than 8 days occurred in $30 \%$ of the studied years each one (see climate from 2005 to 2014 in Figure 2d).

\section{4 | DISCUSSION}

Under stressful conditions, the facilitation of nurse shrubs is critical to ensure tree colonization, especially in areas that lack woody vegetation like abandoned fields. Despite their relevance in forest recovery, we know little about the dynamics of these effects. Our analysis of long-term colonization dynamics of oaks showed that their recruitment accelerated when oaks started recruiting under shrubs. It took 20 years of secondary succession to get to this point, likely when shrub cover and size were large enough to provide a facilitative effect. Our results also showed that evergreen oaks recruited more than deciduous oaks and, against our expectation, only the evergreen species benefited from recruiting under the nurse shrub. Facilitation was more pronounced in years with more arid summers, and the prevailing interaction between the nurse shrub and the evergreen oak switched to competition in wet and mild summers. Our study documented facilitation dynamics for oak recruitment at a single site, but these results could be likely general in the Mediterranean forest context. Still further studies at wider spatial scales with long temporal information would be necessary to corroborate how the nuances of this temporal perspective change.

\section{1 | Long-term dynamics of forest expansion reveal different recruitment pulses of the nurse shrub and oak species}

In accordance with our first hypothesis, the temporal trends in pulses of recruitment that we documented indicate distinct regeneration dynamics for the shrub and the two oak species. Retama sphaerocarpa - a pioneer shrub species- was the earliest colonizer, presumably due to its high dispersion capacity and drought tolerance (Haase, Pugnaire, Clark, \& Incoll, 1999; Haase et al.,
FIGURE 5 Standardized coefficients (parameter $\times$ variable mean) of the climatic variables in the model of Quercus ilex (evergreen oak) recruitment (a; Equation (1) in Data analysis section) and in the model of Quercus faginea (deciduous oak) recruitment (b). Whiskers represent $95 \%$ of the credible interval of the estimated standardized coefficient, and bold whisker segments represent $75 \%$ of the credible interval. The microsite all (open+under shrub) applies to the deciduous oak (a) Evergreen oak

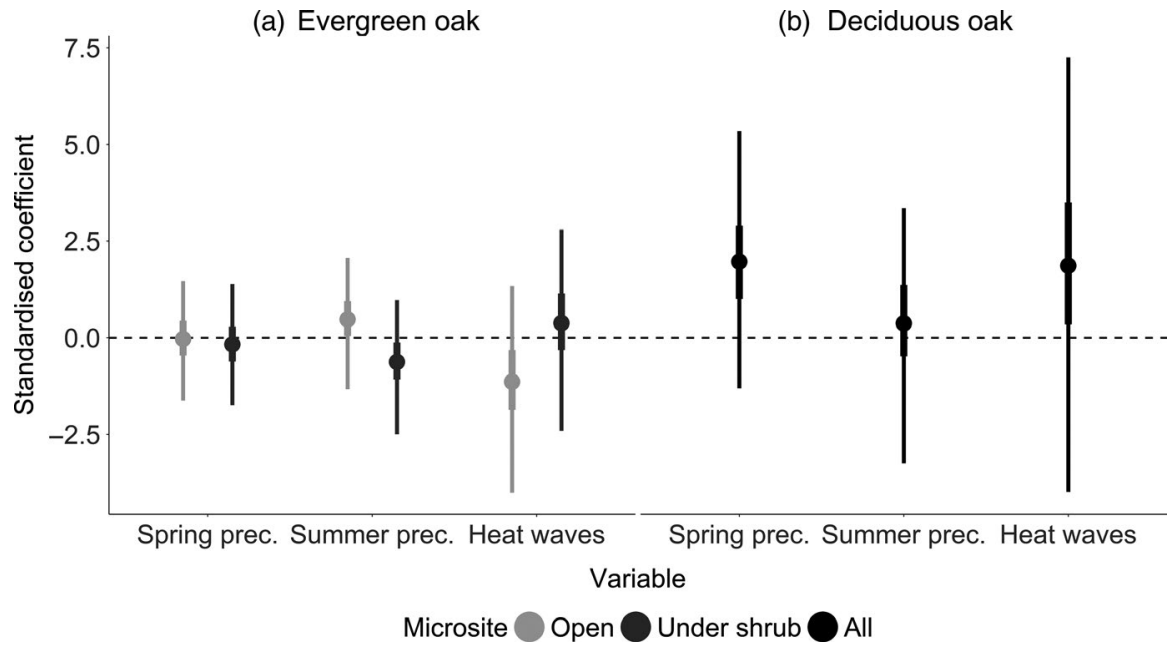



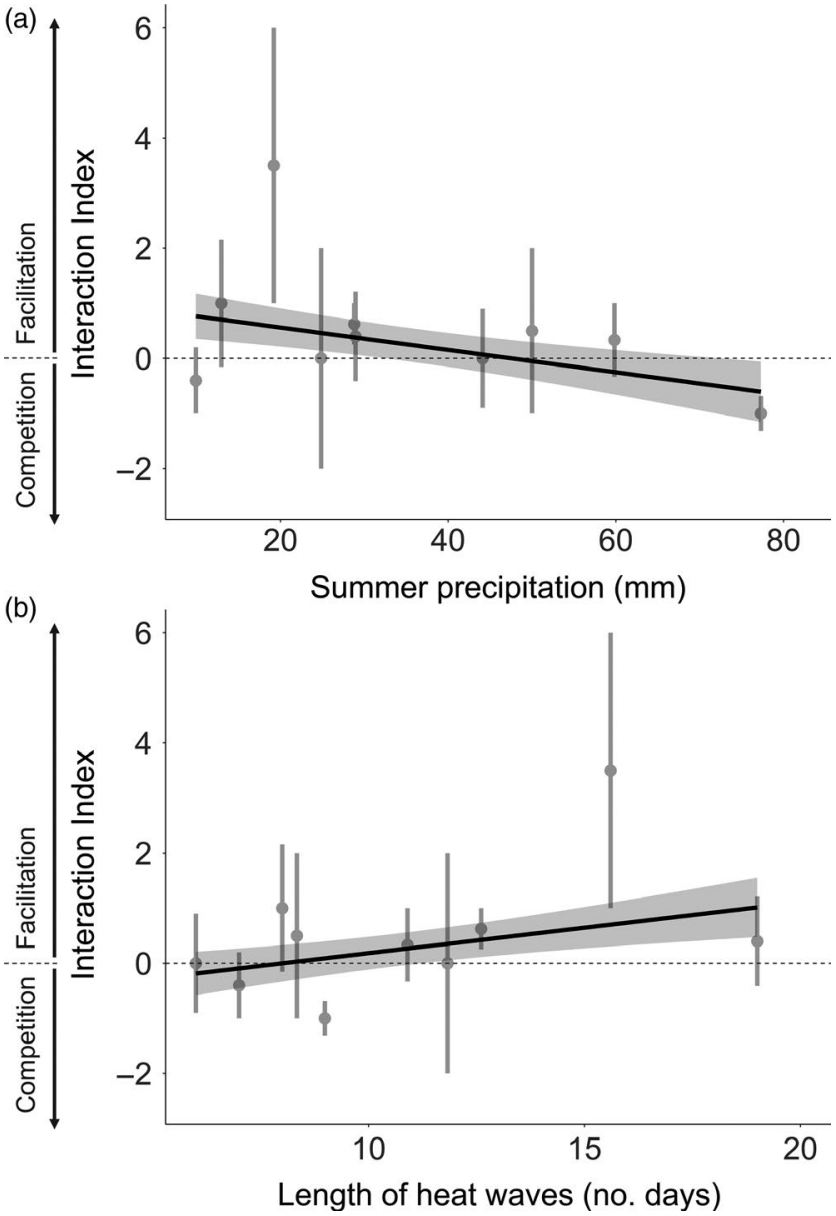

FIGURE 6 Fitted linear model of the relationship between the interaction index of Retama sphaerocarpa and Quercus ilex (evergreen oak) recruitment and (a) summer precipitation or (b) the length of heat waves. The dots are the mean interaction index in the 20 transects per precipitation and length of heat waves level and the whiskers represent the standard errors of the means. Positive values of the interaction index mean facilitation and negative values mean competition

1996; Padilla \& Pugnaire, 2007). Since most juvenile mortality occurs during the first summer in Mediterranean forests (Mendoza, Zamora, et al., 2009; Rey Benayas, Navarro, Espigares, Nicolau, \& Zavala, 2005; Rolo et al., 2013), the large pulse of R. sphaerocarpa recruitment towards the end of the studied period is likely due to the beginning of seed production by already established shrubs, as observed for other plant species (Harper, 1977). The oak recruitment pulses were probably caused by a combination of masting cycles (Koenig, Knops, Carmen, \& Pearse, 2015; PérezRamos et al., 2015), reduced competition with pre-existing plants (herbs in our study; Rey Benayas et al., 2015), and availability of nurse shrubs (Navarro-Cano et al., 2016; Perea et al., 2017). The increase in oak recruitment over time could also be attributed to the greater activity of acorn dispersers and to soil improvement after field abandonment (i.e. increase of $\mathrm{C}: \mathrm{N}$ ratio, organic matter or aggregate stability; Hooker \& Compton, 2003; Rey-Benayas, Galván, \& Carrascal, 2010; Robledano-Aymerich et al., 2014). In particular, the facilitative effects of the shrubs started 20 years after abandonment.

The two oaks also showed differences in their recruitment dynamics, in agreement with hypothesis 1 . In consonance with other studies, the evergreen oak recruited more abundantly, and during longer time windows, than the deciduous oak (Gómez-Aparicio et al., 2004; Perea et al., 2017). Differential drought resistance between these species could be the main cause (Gil-Pelegrín et al., 2017; Montserrat-Martí et al., 2009). Specifically, sensitivity of stomatal conductance to water stress is lower for the evergreen oak than for the deciduous oak (Acherar \& Rambal, 1992; Mediavilla \& Escudero, 2004). Moreover, acorn production and dispersion of the evergreen oak is usually higher than those observed for the deciduous oak (Del Arco, Beltrán, \& Martínez-Ruiz, 2018; Pons \& Pausas, 2007a, 2007b; Rodríguez-Estévez, García, Perea, Mata, \& Gómez-Castro, 2007), and shoots of deciduous oaks are preferred by browsers over shoots of evergreen oaks (Espelta, Habrouk, \& Retana, 2006).

Our results show that after 30 years of succession the evergreen oak (more stress-tolerant) had higher recruitment under the nurse shrub, while most deciduous oak juveniles (less stress-tolerant) recruited in open microsites (91\% of recruited deciduous oak). This unexpected trend (i.e. the more stress-prone species benefits less from facilitation) has also been documented by Plieninger, Rolo, and Moreno (2010) and Torroba-Balmori et al. (2015). The difference between the recruitment microsites of evergreen and deciduous oak does not support our third hypothesis and contradicts a previous study that found similar occurrence of juveniles under shrub and in open areas for both evergreen and deciduous oaks (Perea et al., 2017), as well as the notion that facilitation benefits more the low stress-tolerant and herbivory-prone species (Costa et al., 2017; Madrigal-González, García-Rodríguez, \& Zavala, 2014; Soliveres et al., 2014). The abundance and location patterns of evergreen oak recruitment could be due to the preference of the main dispersers, Garrulus glandarius (European jay) and Apodemus sylvaticus (wood mice), for the evergreen acorns (Del Arco et al., 2018; Pons \& Pausas, 2007a, 2007b), and also to their preference for caching acorns under shrubs (Gomez, 2003; Gómez, Puerta-Piñero, \& Schupp, 2008; Morán-López, Alonso, \& Díaz, 2015). The lack of recruitment of deciduous oaks under shrubs could be also due to strong competition between the $R$. sphaerocarpa and the deciduous oak or to insufficient facilitation effect (Alday et al., 2016; Plieninger et al., 2010). Future experiments should further assess the underlying mechanisms of the recruitment differences between these two oak species.

For the evergreen oak, the recruitment under shrub was sustained over time in comparison to the pulse patterns observed in open areas. These dynamics may indicate that facilitation can increase the window of opportunity for evergreen oak colonization, which is probably due to both direct and indirect facilitation mediated by $R$. sphaerocarpa (Cuesta et al., 2010; Prieto et al., 2011). However, we could not quantify which proportion of the recruitment under shrub through time was due to the lower extension of open areas. The facilitation 
of the evergreen oak together with the low recruitment of deciduous oaks observed suggest a more likely future dominance of evergreen oaks in Mediterranean abandoned fields (Perea et al., 2017).

\section{2 | Relationship between retama population structure and oak facilitation}

It is likely that direct and indirect facilitative mechanisms increase with nurse size and abundance (Allegrezza et al., 2016; Cuesta et al., 2010; Gómez et al., 2008; Navarro-Cano et al., 2016). Our results document the lagged facilitation effect associated with the shrub size and population structure (hypothesis 2). This hypothesis coincides with the results of Ramírez and Díaz (2008), that documented an acceleration of Q. ilex recruitment after 15 years of abandonment and its positive relationship with the cover of a leguminous shrub. The $R$. sphaerocarpa canopy cover was in average $2.21 \%$ at the beginning and acceleration of oak recruitment under shrub, which highlights the high facilitative capacity of this species.

Retama sphaerocarpa started effectively facilitating oak recruitment 20 years after shrubland recovery, and shrubs reached a threshold size of $74 \mathrm{~cm}$ in crown diameter. Recruitment rates under shrub were maximum at intermediate shrub sizes. The predominance of medium-sized individuals among the nurse shrubs suggests that facilitation under the shrub peaks and levels off once the shrub attains certain size (Navarro-Cano et al., 2016). At this point, the microclimatic conditions under the shrub canopy may be more moderate than outside, the soil may be specially enriched and structured or the shrub could attract dispersers for hiding and acorn caching (Gomez, 2003; Gómez et al., 2008; Pugnaire et al., 1996). Shrubs older than 21 years frequently had irregular and open canopies linked to branch senescence (V. CruzAlonso personal observation). This canopy opening could deteriorate the microclimate under the shrub and the physical protection against browsers (Schöb, Armas, Guler, Prieto, \& Pugnaire, 2013), reducing the facilitation capacity of the older and/or larger shrubs. The $R$. sphaerocarpa size threshold for oak facilitation was reached when they were 7-8 years old, but the first oak recorded under shrub occurred 20 years after field abandonment. The lag between reaching a shrub structure able to facilitate oak recruitment and the effective facilitation suggests that recovery of other general ecosystem properties, further than the microenvironment created by the shrubs, such as soil structure and organic matter after agriculture ceased (Robledano-Aymerich et al., 2014), may also be needed for oak recruitment under nurse shrubs.

\subsection{Climate modulates the facilitative effect on oak recruitment}

We could not find a clear support for the hypothesis that $R$. sphaerocarpa buffers the climate effect on oak recruitment since this effect did not differ between microsites. However, our analysis showed that the facilitative effect of $R$. sphaerocarpa on the evergreen oak was stronger (i.e. the interaction index was more positive) in years with more arid summers, whereas competition prevailed in wet and mild summers. These results support the Stress Gradient Hypothesis (Bertness \&
Callaway, 1994; He, Bertness, \& Altieri, 2013). The herb community that usually dries out in summer could grow longer under the $R$. sphaerocarpa shade in milder summers, and thus increase competition with oak seedlings (Tielborger \& Kadmon, 2000). Surprisingly, we did not find any significant effects of spring precipitation or summer conditions on oak recruitment. The lack of a climatic effect could be due to limitations of our study, which might need additional data and not take into account other processes that might affect recruitment, such us mortality in later years (Debussche \& Lepart, 1992). Moreover, modelling results may be affected by the non-inclusion of variables such as acorn production, abundance of dispersers and soil features which vary from year to year (Koenig et al., 2013; Rey-Benayas et al., 2010; Robledano-Aymerich et al., 2014).

\section{5 | CONCLUSIONS}

Long-term forest recovery in the studied Mediterranean abandoned fields exhibited differential pulses of woody species recruitment. Despite being closely related, oaks with contrasting leaf traits (evergreen vs. deciduous) and drought tolerance showed different patterns of recruitment. The $R$. sphaerocarpa shrubland buffered Q. ilex recruitment pulses, that is, recruitment rate under the nurse was maintained during periods of low recruitment in open microsites. The deciduous oak had lower recruitment than the evergreen oak during the first 30 years of forest succession and we could not document a positive effect of $R$. sphaerocarpa on recruitment of the deciduous oak. The nurse shrub population developed for 20 years before facilitating oak establishment and oak recruits appeared preferably in medium and big shrubs, always older than 7 years. The facilitative effect of $R$. sphaerocarpa increased with summer aridity. These results suggest a potential dominance of evergreen oaks in restored secondary forests in the mid-term under more arid climate scenarios and show that less stress tolerant species do not necessarily benefit more from facilitative interactions.

\section{ACKNOWLEDGEMENTS}

This study was supported by the Madrid Government projects REMEDINAL-3 S2013/MAE-2719 and REMEDINAL TE-CM S2018/EMT-4338, and a contract between the FIRE (Fundación Internacional para la Restauración de Ecosistemas; https://www. fundacionfire.org/) and the University of Alcalá (FIRE-UAH 127/2017). VCA was supported by the Environmental Fellowship Programme of 'Tatiana Pérez de Guzmán el Bueno' Foundation (2015; http://fundaciontatianapgb.org/) and the REMEDINAL Postdoctoral Fellowship Programme (TE-CM S2018/EMT-4338). PRB was supported by the TALENTO Fellow Programme (Madrid Government, 2016-T2/AMB-1665). We thank the Spanish Ministry of Defence, especially to Inés Cava for assisting in access to field sites. We thank Daniel Gómez, Adrián Eceolaza, Fernando Viñegla, Pablo Quiles, Paloma Díaz and Julen Astigarraga their help with 
field work, sample processing and plant dating; Asun Rodríguez for the help during the early stages of the work; Guillermo Bodega for kindly sharing his knowledge and lab equipment for histology processing; M. Luisa Aranda for facilitating the use of her laboratory microscope; Claudia and Cristina Miguel from the Cell Cultures Centre of the University of Alcalá, and Manuel Báez for their collaboration during the sample processing. Finally, we are very grateful to Jaime Madrigal, Enrique Andivia, Patricia González and Laura Fernández for their disinterested availability to solve any doubt about sample processing and dendrochronology. We acknowledge the input from three anonymous reviewers that improved the final version of this manuscript.

\section{AUTHORS' CONTRIBUTION}

V.C.-A., P.V.-S., P.R.-B. and J.M.R.-B. conceived the ideas and designed the methodology; V.C.-A. and P.V.-S. collected the data; V.C.-A., II and P.R.-B. analysed the data; V.C.-A. and P.V.-S. led the writing of the manuscript. All authors contributed critically to the drafts and gave final approval for publication.

\section{ORCID}

Verónica Cruz-Alonso iD https://orcid.org/0000-0002-0642-036X

Pedro Villar-Salvador (iD https://orcid.org/0000-0001-9338-4530

Paloma Ruiz-Benito (iD https://orcid.org/0000-0002-2781-5870

Inés Ibáñez iD https://orcid.org/0000-0002-1054-0727

José M. Rey-Benayas (iD https://orcid.org/0000-0002-2099-8512

\section{DATA AVAILABILITY STATEMENT}

Data available via Figshare: https://doi.org/10.6084/m9.figsh are.9744953.v1 (Cruz-Alonso, Villar-Salvador, Ruiz-Benito, Ibañez, \& Rey Benayas, 2019).

\section{REFERENCES}

Acherar, M., \& Rambal, S. (1992). Comparative water relations of four Mediterranean oak species. In F. Romane, \& J. Terradas (Eds.), Quercus ilex L. ecosystems: Function, dynamics and management (Vol. 99-100, pp. 177-184). Dordrecht, Netherlands: Springer. https://doi. org/10.1007/978-94-017-2836-2

Alday, J. G., Zaldívar, P., Torroba-Balmori, P., Fernández-Santos, B., \& Martínez-Ruiz, C. (2016). Natural forest expansion on reclaimed coal mines in Northern Spain: The role of native shrubs as suitable microsites. Environmental Science and Pollution Research, 23(14), 1360613616. https://doi.org/10.1007/s11356-015-5681-2

Allegrezza, M., Corti, G., Cocco, S., Pesaresi, S., Chirico, G. B., Saracino, A., \& Bonanomi, G. (2016). Microclimate buffering and fertility island formation during Juniperus communis ontogenesis modulate competition-facilitation balance. Journal of Vegetation Science, 27(3), 616-627. https://doi.org/10.1111/jvs.12386

Andivia, E., Villar-Salvador, P., Tovar, L., Rabasa, S., \& Rey-Benayas, J. M. (2017). Multiscale assessment of woody species recruitment in Mediterranean shrublands: Facilitation and beyond. Journal of Vegetation Science, 28(3), 639-648. https://doi.org/10.1111/ jvs.12520

Bates, D., Maechler, M., Bolker, B., Walker, S., Christensen, R. H. B., Singmann, H., Green, P. (2017). Ime4. Linear Mixed-Effects Models using "Eigen" and S4. Retrieved from http://Ime4.r-forge.r-proje ct.org/\%OD

Bertness, M. D., \& Callaway, R. M. (1994). Positive interactions in communities. Trends in Ecology and Evolution, 9(5), 191-193. https://doi. org/10.1016/0169-5347(94)90088-4

Bruno, J. F., Stachowicz, J. J., \& Bertness, M. D. (2003). Inclusion of facilitation into ecological theory. Trends in Ecology \& Evolution, 18(3), 119-125. https://doi.org/10.1016/S0169-5347(02)00045-9

Burnham, K. P., \& Anderson, D. R. (2002). Model selection and multimodel inference: A practical information-theoretic approach. New York: Springer-Verlag. https://doi.org/10.1016/j.ecolmodel.2003.11.004

Butterfield, B. J., Betancourt, J. L., Turner, R. M., John, M., Butterfield, B. J., Betancourt, J. L., ... Briggs, J. M. (2010). Facilitation drives 65 years of vegetation change in the Sonoran Desert. Ecological Society of America, 91(4), 1132-1139. https://doi.org/10.1890/09-0145.1

Castro-Díez, P., \& Montserrat-Martí, G. (1998). Phenological pattern of fifteen Mediterranean phanaerophytes from Quercus ilex communities of NE-Spain. Plant Ecology, 139(1), 103-112. https://doi. org/10.1023/A:1009759318927

Castro-Díez, P., Villar-Salvador, P., Pérez-Rontomé, C., Maestro-Martínez, M., \& Montserrat-Martí, G. (1997). Leaf morphology and leaf chemical composition in three Quercus (Fagaceae) species along a rainfall gradient in NE Spain. Trees, 11(3), 127-134. https://doi.org/10.1007/ pl00009662

Connell, J. H., \& Slatyer, R. O. (1977). Mechanisms of succession in natural communities and their role in community stability and organisation. The American Naturalist, 111(982), 1119-1144. https://doi. org/10.1086/283241

Corcuera, L., Camarero, J. J., \& Gil-Pelegrín, E. (2002). Functional groups in Quercus species derived from the analysis of pressurevolume curves. Trees, 16(7), 465-472. https://doi.org/10.1007/ s00468-002-0187-1

R Core Team. (2017). R: A language and environment for statistical computing. Vienna: R Foundation for Statistical Computing.

Costa, A., Villa, S., Alonso, P., García-Rodríguez, J. A., Martín, F. J., Martínez-Ruiz, C., \& Fernández-Santos, B. (2017). Can native shrubs facilitate the early establishment of contrasted co-occurring oaks in Mediterranean grazed areas? Journal of Vegetation Science, 28(5), 1047-1056. https://doi.org/10.1111/jvs.12550

Cruz-Alonso, V., Villar-Salvador, P., Ruiz-Benito, P., Ibañez, I., \& Rey Benayas, J. M. (2019). Data from: Long-term dynamics of shrub facilitation shape the mixing of evergreen and deciduous oaks in Mediterranean abandoned fields. Figshare, https://doi.org/10.6084/ m9.figshare.9744953.v1

Cuesta, B., Villar-Salvador, P., Puértolas, J., Rey Benayas, J. M., \& Michalet, R. (2010). Facilitation of Quercus ilex in Mediterranean shrubland is explained by both direct and indirect interactions mediated by herbs. Journal of Ecology, 98(3), 687-696. https://doi. org/10.1111/j.1365-2745.2010.01655.x

De Cáceres, M., Martin, N., Granda, V., \& Cabon, A. (2018). meteoland: Landscape Meteorology Tools. R Package Version 0.7.1. Retrieved from https://cran.r-project.org/package=meteoland

Debussche, M., \& Lepart, J. (1992). Establishment of woody plants in mediterranan old fields: Opportunity in space and time. Landscape Ecology, 6(3), 133-145.

Del Arco, J. M., Beltrán, D., \& Martínez-Ruiz, C. (2018). Risk for the natural regeneration of Quercus species due to the expansion of rodent species (Microtus arvalis). Behavioral Ecology and Sociobiology, 72(10), 160. https://doi.org/10.1007/s00265-018-2575-6

Dormann, C. F., Elith, J., Bacher, S., Buchmann, C., Carl, G., Carré, G., ... Lautenbach, S. (2013). Collinearity: A 
review of methods to deal with it and a simulation study evaluating their performance. Ecography, 36(1), 027-046. https://doi. $\operatorname{org} / 10.1111 / \mathrm{j} .1600-0587.2012 .07348 . x$

Espelta, J. M., Habrouk, A., \& Retana, J. (2006). Response to natural and simulated browsing of two Mediterranean oaks with contrasting leaf habit after a wildfire. Annals of Forest Science, 63(4), 441-447. https ://doi.org/10.1051/forest:2006024

Gil-Pelegrín, E., Peguero-Pina, J. J., \& Sancho-Knapik, D. (2017). Oaks Physiological Ecology. Exploring the Functional Diversity of Genus Quercus L (Vol. 7). Cham: Springer International Publishing. https:// doi.org/10.1007/978-3-319-69099-5

Giorgi, F., \& Lionello, P. (2008). Climate change projections for the Mediterranean region. Global and Planetary Change, 63(2-3), 90-104. https://doi.org/10.1016/j.gloplacha.2007.09.005

Gomez, J. M. (2003). Spatial patterns in long-distance dispersal of Quercus ilex acorns by jays in a heterogeneous landscape. Ecography, 26(5), 573-584. https://doi.org/10.1034/j.1600-0587.2003.03586.x

Gómez, J. M., Puerta-Piñero, C., \& Schupp, E. W. (2008). Effectiveness of rodents as local seed dispersers of Holm oaks. Oecologia, 155(3), 529-537. https://doi.org/10.1007/s00442-007-0928-3

Gómez-Aparicio, L. (2009). The role of plant interactions in the restoration of degraded ecosystems: A meta-analysis across life-forms and ecosystems. Journal of Ecology, 97(6), 1202-1214. https://doi. org/10.1111/j.1365-2745.2009.01573.x

Gómez-Aparicio, L., Zamora, R., Castro, J., \& Hódar, J. A. (2008). Facilitation of tree saplings by nurse plants: Microhabitat amelioration or protection against herbivores? Journal of Vegetation Science, 19(2), 161-172. https://doi.org/10.3170/2008-8-18347

Gómez-Aparicio, L., Zamora, R., Gómez, J. M., Hódar, J. A., \& Castro, J. (2004). Applying plant facilitation to forest restoration in mediterranean ecosystems: A meta-analysis of the shrubs as nurse plants. Ecological Applications, 14(4), 1118-1138. https://doi. org/10.1890/03-5084

Haase, P., Pugnaire, F. I., Clark, S. C., \& Incoll, L. D. (1999). Diurnal and seasonal changes in cladode photosynthetic rate in relation to canopy age structure in the leguminous shrub Retama sphaerocarpa. Functional Ecology, 13(5), 640-649. https://doi. org/10.1046/j.1365-2435.1999.00365.x

Haase, P., Pugnaire, F. I., Fernández, E. M., Puigdefábregas, J., Clark, S. C., \& Incoll, L. D. (1996). An investigation of rooting depth of the semiarid shrub Retama sphaerocarpa (L.) Boiss. by labelling of ground water with a chemical tracer. Journal of Hydrology, 177(1-2), 23-31. https://doi.org/10.1016/0022-1694(95)02794-7

Harper, J. L. (1977). Population biology of plants. London: Academic Press. Hastie, T. (2018). Generalized Additive Models. R Package Version1.15. Retrieved from https://cran.r-project.org/package=gam

He, Q., Bertness, M. D., \& Altieri, A. H. (2013). Global shifts towards positive species interactions with increasing environmental stress. Ecology Letters, 16(5), 695-706. https://doi.org/10.1111/ele.12080

Hooker, T. D., \& Compton, J. E. (2003). Forest ecosystem carbon and nitrogen accumulation during the first century after agricultural abandonment. Ecological Applications, 13(2), 299-313. https://doi.org/10. 1890/1051-0761(2003)013[0299:FECANA]2.0.CO;2

Joffre, R., Rambal, S., \& Damesin, C. (2007). Functional attributes in Mediterranean-type ecosystems. In F. Valladares, \& F. Pugnaire (Eds.), Functional plant ecology (pp. 285-312). Boca raton, FL: CRC Press.

Kéry, M. (2010). Introduction to WinBUGS for ecologists: Bayesian approach to regression, ANOVA, mixed models and related analyses. Cambridge, MA: Academic Press.

Killick, R., Haynes, K., \& Eckley, I. (2016)._changepoint: An R package for changepoint analysis. Retrieved fromhttps://cran.r-project.org/ package $=$ changepoint

Koenig, W. D., Díaz, M., Pulido, F., Alejano, R., Beamonte, E., \& Knops, J. M. H. (2013). Acorn production patterns. In P.
Campos, L. Huntsinger, J. L. Oviedo Pro, P. F. Starrs, M. Diaz, R. B. Standiford, \& G. Montero (Eds.), Mediterranean oak woodland working landscapes: Dehesas of Spain and ranchlands of California (pp. 181-209). Dordrecht, Netherlands: Springer. https://doi. org/10.1007/978-94-007-6707-2_7

Koenig, W. D., Knops, J. M. H., Carmen, W. J., \& Pearse, I. S. (2015). What drives masting? The phenological synchrony hypothesis. Ecology, 96(1), 184-192. https://doi.org/10.1890/14-0819.1

Kouba, Y., Camarero, J. J., \& Alados, C. L. (2012). Roles of land-use and climate change on the establishment and regeneration dynamics of Mediterranean semi-deciduous oak forests. Forest Ecology and Management, 274, 143-150. https://doi.org/10.1016/j. foreco.2012.02.033

Liancourt, P., Callaway, R. M., \& Michalet, R. (2005). Stress tolerance and competitive-response ability determine the outcome of biotic interactions. Ecology, 86(6), 1611-1618. https://doi.org/10.1890/04-1398

Lortie, C. J., Brooker, R. W., Choler, P., Kikvidze, Z., Pugnaire, F. I., Callaway, R. M., ... Lortie, J. (2004). Rethinking plant community theory. Oikos, 107(2), 433-438. https://doi. org/10.1111/j.0030-1299.2004.13250.x

Madrigal-González, J., García-Rodríguez, J. A., \& Zavala, M. A. (2014). Shrub encroachment shifts the bioclimatic limit between marcescent and sclerophyllous oaks along an elevation gradient in west-central Spain. Journal of Vegetation Science, 25(2), 514-524. https://doi. org/10.1111/jvs.12088

Madrigal-González, J., Ruiz-Benito, P., Ratcliffe, S., Rigling, A., Wirth, C., Zimmermann, N. E., ... Zavala, M. A. (2017). Competition drives oak species distribution and functioning in Europe: Implications under global change. In I. E. Gil-Pelegrín, J. J. Peguero-Pina, \& D. SanchoKnapik (Eds.), Oaks physiological ecology. Exploring the functional diversity of genus Quercus L. (pp. 513-538). Berlin: Springer International Publishing.

Maestre, F. T., Callaway, R. M., Valladares, F., \& Lortie, C. J. (2009). Refining the stress-gradient hypothesis for competition and facilitation in plant communities. Journal of Ecology, 97(2), 199-205. https:// doi.org/10.1111/j.1365-2745.2008.01476.x

Maestre, F. T., Valladares, F., \& Reynolds, J. F. (2005). Is the change of plant-plant interactions with abiotic stress predictable? A meta-analysis of field results in arid environments. Journal of Ecology, 93(4), 748-757. https://doi.org/10.1111/j.1365-2745.2005.01017.x

Mediavilla, S., \& Escudero, A. (2004). Stomatal responses to drought of mature trees and seedlings of two co-occurring Mediterranean oaks. Forest Ecology and Management, 187(2-3), 281-294. https://doi. org/10.1016/j.foreco.2003.07.006

Mendoza, I., Gómez-Aparicio, L., Zamora, R., \& Matías, L. (2009). Recruitment limitation of forest communities in a degraded Mediterranean landscape. Journal of Vegetation Science, 20(2), 367376. https://doi.org/10.1111/j.1654-1103.2009.05705.x

Mendoza, I., Zamora, R., \& Castro, J. (2009). A seeding experiment for testing tree-community recruitment under variable environments: Implications for forest regeneration and conservation in Mediterranean habitats. Biological Conservation, 142(7), 1491-1499. https://doi.org/10.1016/j.biocon.2009.02.018

Montserrat-Martí, G., Camarero, J. J., Palacio, S., Pérez-Rontomé, C., Milla, R., Albuixech, J., \& Maestro, M. (2009). Summer-drought constrains the phenology and growth of two coexisting Mediterranean oaks with contrasting leaf habit: Implications for their persistence and reproduction. Trees - Structure and Function, 23(4), 787-799. https://doi.org/10.1007/s00468-009-0320-5

Morán-López, T., Alonso, C. L., \& Díaz, M. (2015). Landscape effects on jay foraging behavior decrease acorn dispersal services in dehesas. Acta Oecologica, 69, 52-64. https://doi.org/10.1016/j.actao.2015.07.006

Moreno-Gutiérrez, C., Battipaglia, G., Cherubini, P., Delgado Huertas, A., \& Querejeta, J. I. (2015). Pine afforestation decreases the long-term performance of understorey shrubs in a semi-arid Mediterranean 
ecosystem: A stable isotope approach. Functional Ecology, 29(1), 1525. https://doi.org/10.1111/1365-2435.12311

Navarro-Cano, J. A., Goberna, M., Valiente-Banuet, A., \& Verdú, M. (2016). Same nurse but different time: Temporal divergence in the facilitation of plant lineages with contrasted functional syndromes. Functional Ecology, 30(11), 1854-1861. https://doi. org/10.1111/1365-2435.12660

Padilla, F. M., \& Pugnaire, F. I. (2007). Rooting depth and soil moisture control Mediterranean woody seedling survival during drought. Functional Ecology, 21(3), 489-495. https://doi. org/10.1111/j.1365-2435.2007.01267.x

Peñuelas-Rubira, J. L., Ocaña-Bueno, L., Domínguez-Lerena, S., RenillaEstrada, I., Peñuelas, J. L., Ocaña, L., ... Renilla, I. (1996). Experiencias sobre el control de la competencia herbácea en repoblaciones de terrenos agrícolas abandonados. Montes, 45, 30-36.

Perea, R., López-Sánchez, A., \& Dirzo, R. (2017). Differential tree recruitment in California oak savannas: Are evergreen oaks replacing deciduous oaks? Forest Ecology and Management, 399, 1-8. https://doi. org/10.1016/j.foreco.2017.05.018

Pérez-Ramos, I. M., Padilla-Díaz, C. M., Koenig, W. D., \& Marañón, T. (2015). Environmental drivers of mast-seeding in Mediterranean oak species: Does leaf habit matter? Journal of Ecology, 103(3), 691-700. https://doi.org/10.1111/1365-2745.12400

Plieninger, T., Rolo, V., \& Moreno, G. (2010). Large-scale patterns of Quercus ilex, Quercus suber, and Quercus pyrenaica regeneration in central-western Spain. Ecosystems, 13(5), 644-660. https://doi. org/10.1007/s10021-010-9345-2

Plummer, M. (2016). rjags: Bayesian Graphical Models using MCMC. Retrieved from https://cran.r-project.org/package=rjags

Pons, J., \& Pausas, J. G. (2007a). Not only size matters: Acorn selection by the European jay (Garrulus glandarius). Acta Oecologica, 31(3), 353360. https://doi.org/10.1016/j.actao.2007.01.004

Pons, J., \& Pausas, J. G. (2007b). Rodent acorn selection in a Mediterranean oak landscape. Ecological Research, 22(4), 535-541. https://doi.org/10.1007/s11284-006-0053-5

Prieto, I., Kikvidze, Z., \& Pugnaire, F. I. (2010). Hydraulic lift: Soil processes and transpiration in the Mediterranean leguminous shrub Retama sphaerocarpa (L.) Boiss. Plant and Soil, 329(1-2), 447-456. https://doi.org/10.1007/s11104-009-0170-3

Prieto, I., Padilla, F. M., Armas, C., \& Pugnaire, F. I. (2011). The role of hydraulic lift on seedling establishment under a nurse plant species in a semi-arid environment. Perspectives in Plant Ecology Evolution and Systematics, 13(3), 181-187. https://doi.org/10.1016/j. ppees.2011.05.002

Pugnaire, F. I., Haase, P., Puigdefábregas, J., Cueto, M., Clark, S. C., Incoll, L. D., \& Puigdefabregas, J. (1996). Facilitation and Succession under the Canopy of a Leguminous Shrub, Retama sphaerocarpa, in a SemiArid Environment in South-East Spain. Oikos, 76(3), 455. https://doi. org/10.2307/3546339

Pugnaire, F. I., Luque, M. T., Armas, C., \& Gutiérrez, L. (2006). Colonization processes in semi-arid Mediterranean old-fields. Journal of Arid Environments, 65(4), 591-603. https://doi.org/10.1016/j.jarid env.2005.10.002

Pulsford, S. A., Lindenmayer, D. B., \& Driscoll, D. A. (2016). A succession of theories: Purging redundancy from disturbance theory. Biological Reviews, 91(1), 148-167. https://doi.org/10.1111/brv.12163

Quero, J. L., Villar, R., Marañón, T., \& Zamora, R. (2006). Interactions of drought and shade effects on seedlings of four Quercus species: Physiological and structural leaf responses. New Phytologist, 170(4), 819-834. https://doi.org/10.1111/j.1469-8137.2006.01713.x

Ramírez, J. A., \& Díaz, M. (2008). The role of temporal shrub encroachment for the maintenance of Spanish holm oak Quercus ilex dehesas. Forest Ecology and Management, 255(5-6), 1976-1983. https://doi. org/10.1016/j.foreco.2007.12.019
Rey Benayas, J. M., Martínez-Baroja, L., Pérez-Camacho, L., VillarSalvador, P., \& Holl, K. D. (2015). Predation and aridity slow down the spread of 21-year-old planted woodland islets in restored Mediterranean farmland. New Forests, 46(5-6), 841-853. https://doi. org/10.1007/s11056-015-9490-8

Rey Benayas, J. M., Navarro, J., Espigares, T., Nicolau, J. M., \& Zavala, M. A. (2005). Effects of artificial shading and weed mowing in reforestation of Mediterranean abandoned cropland with contrasting Quercus species. Forest Ecology and Management, 212(1-3), 302-314. https://doi.org/10.1016/j.foreco.2005.03.032

Rey-Benayas, J. M., Galván, I., \& Carrascal, L. M. (2010). Differential effects of vegetation restoration in Mediterranean abandoned cropland by secondary succession and pine plantations on bird assemblages. Forest Ecology and Management, 260(1), 87-95. https://doi. org/10.1016/j.foreco.2010.04.004

Robledano-Aymerich, F., Romero-Díaz, A., Belmonte-Serrato, F., Zapata-Pérez, V. M., Martínez-Hernández, C., \& Martínez-López, V. (2014). Ecogeomorphological consequences of land abandonment in semiarid Mediterranean areas: Integrated assessment of physical evolution and biodiversity. Agriculture, Ecosystems and Environment, 197, 222-242. https://doi.org/10.1016/j. agee.2014.08.006

Rodríguez-Estévez, V., García, A., Perea, J., Mata, C., \& Gómez-Castro, A. G. (2007). Producción de bellota en la dehesa: Factores influyentes. Archivos De Zootecnia, 56, 25-43.

Rolo, V., Plieninger, T., \& Moreno, G. (2013). Facilitation of holm oak recruitment through two contrasted shrubs species in Mediterranean grazed woodlands. Journal of Vegetation Science, 24(2), 344-355. https://doi.org/10.1111/j.1654-1103.2012.01458.x

Rousset, O., \& Lepart, J. (2000). Positive and negative interactions at different life stages of a colonizing species (Quercus humilis). Journal of Ecology, 88(3), 401-412. https://doi. org/10.1046/j.1365-2745.2000.00457.x

Sánchez-Gómez, D., Valladares, F., \& Zavala, M. A. (2006). Performance of seedlings of Mediterranean woody species under experimental gradients of irradiance and water availability: Trade-offs and evidence for niche differentiation. New Phytologist, 170(4), 795-806. https://doi.org/10.1111/j.1469-8137.2006.01711.x

Schöb, C., Armas, C., Guler, M., Prieto, I., \& Pugnaire, F. I. (2013). Variability in functional traits mediates plant interactions along stress gradients. Journal of Ecology, 101(3), 753-762. https://doi. org/10.1111/1365-2745.12062

Simpson, D., Rue, H., Martins, T. G., Riebler, A., \& Sørbye, S. H. (2015). Penalising model component complexity: A principled, practical approach to constructing priors. Statistical Science, 32(1), 1-28.

Smit, C., Díaz, M., \& Jansen, P. (2009). Establishment limitation of holm oak (Quercus ilex subsp. ballota (Desf.) Samp.) in a Mediterranean savanna - forest ecosystem. Annals of Forest Science, 66(5), 511-511. https://doi.org/10.1051/forest/2009028

Smit, C., Ouden, J., \& Díaz, M. (2008). Facilitation of Quercus ilex recruitment by shrubs in Mediterranean open woodlands. Journal of Vegetation Science, 19(2), 193-200. https://doi. org/10.3170/2007-8-18352

Soliveres, S., Maestre, F. T., Bowker, M. A., Torices, R., Quero, J. L., García-Gómez, M., ... Noumi, Z. (2014). Functional traits determine plant co-occurrence more than environment or evolutionary relatedness in global drylands. Perspectives in Plant Ecology, Evolution and Systematics, 16(4), 164-173. https://doi.org/10.1016/j. ppees.2014.05.001

Thorson, J. T., Punt, A. E., \& Nel, R. (2012). Evaluating population recovery for sea turtles under nesting beach protection while accounting for nesting behaviours and changes in availability. Journal of Applied Ecology, 49(3), 601-610. https://doi. org/10.1111/j.1365-2664.2012.02143.x 
Tielborger, K., \& Kadmon, R. (2000). Temporal environmental variation tips the balance between facilitation and interference in desert plants. Ecology, 81(6), 1544-1553. https://doi. org/10.1890/0012-9658(2000)

Tornero Sánchez, J. (1998). La comarca de Uceda; el campo de adiestramiento paracaidista y sus valores ambientales. Ministerio de Defensa. Secretaría General Técnica.

Torroba-Balmori, P., Zaldívar, P., Alday, J. G., Fernández-Santos, B., \& Martínez-Ruiz, C. (2015). Recovering Quercus species on reclaimed coal wastes using native shrubs as restoration nurse plants. Ecological Engineering, 77, 146-153. https://doi.org/10.1016/j.ecole ng.2015.01.024

\section{SUPPORTING INFORMATION}

Additional supporting information may be found online in the Supporting Information section.

How to cite this article: Cruz-Alonso V, Villar-Salvador P, RuizBenito P, Ibañez I, Rey-Benayas JM. Long-term dynamics of shrub facilitation shape the mixing of evergreen and deciduous oaks in Mediterranean abandoned fields. J Ecol. 2020;108:11251137. https://doi.org/10.1111/1365-2745.13309 